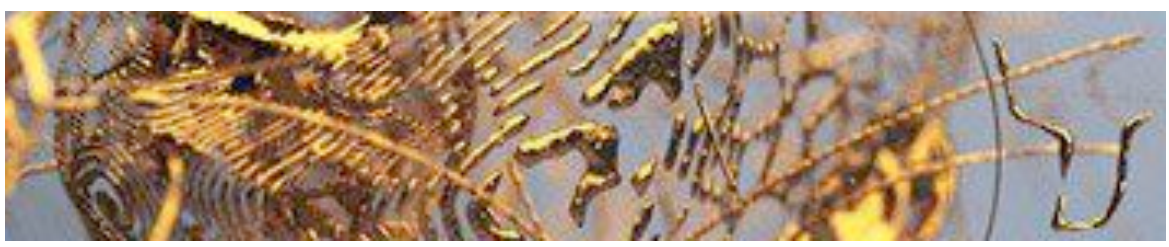

\title{
La investigación-creación en el contexto de las prácticas estético-artísticas contemporáneas. Desplazamientos disciplinares y desafíos institucionales
}

\section{Research-creation in the context of the contemporaneous esthetic-artistic practices. Disciplinary displacements and institutional challenges}

Calle, Margarita ${ }^{(*)}$

Universidad Tecnológica de Pereira - Colombia aumar@utp.edu.co

\begin{abstract}
Resumen
En este texto nos ocuparemos de visibilizar algunos de los desplazamientos más significativos que han sufrido las prácticas estético-artísticas, enfatizando en el modo como estas aperturas han aportado a la configuración de una cierta noción de investigación-creación, en un momento las creaciones artísticas aparecen imbricadas en un campo complejo de relaciones conformado por saberes, tradiciones, instituciones y efectos pragmáticos, que hacen de tales prácticas una auténti-
\end{abstract}

\begin{abstract}
In this text we will deal with the visibilization of some of the most significant displacements that the esthetic-artistic practices have gone through, emphasizing in the way in which these apertures have contributed to the configuration of certain notion of research-creation, at a time when the artisitic creations appear imbricated in a complex field of relationships made up of perceptions, traditions, institutions and pragmatic effects, which make of such practices an authen-
\end{abstract}


«La investigación-creación en el contexto de las prácticas estético-artísticas...»

ca sedimentación de lo que podemos reconocer como procesos culturales.

Palabras clave: arte contemporáneo, investigar-crear, prácticas estéticas y artísticas. tic sedementation of what we can recognize as cultural processes.

Keywords: Contemporary Art, Research-Creation, Creation, Esthetic and Artistic Practices.

Mediaciones Sociales, № 12, 2013, pp. 65-79. ISSN electrónico: 1989-0494.

DOI: http://dx.doi.org/10.5209/rev_MESO.2013.n12.45263 
«La investigación-creación en el contexto de las prácticas estético-artísticas...»

\section{Casi toda obra seria de arte contemporáneo recapitula, en algún nivel implícito o explícito, el orden histórico a que pertenece. La conciencia de lo precedente ha llegado a ser casi la condición y la definición de las ambiciones artísticas mayores.}

Thomas Crow

\section{INTRODUCCIÓN}

Hasta bien avanzado el siglo XX, el abordaje de los problemas vinculados al campo de la estética y la creación se desplazaron dentro de marcos interpretativos y procedimentales, que optaron por privilegiar unas epistemes y unas estructuras conformativas en detrimento de otras. En nuestro momento actual tales procesos han sido objeto de aperturas y replanteamientos que han colocado la investigación-creación en un campo de cruces e intercambios disciplinares que buscan validar nuevos modos de identificar significados y construir posturas alrededor de los fenómenos del arte, la estética y la cultura. En coherencia con estas dinámicas, en este texto nos ocuparemos de visibilizar la concreción de tales desplazamientos, con miras a despejar posibles rutas para abordar los procesos de investigación-creación en una época en la que las prácticas estético-artísticas aparecen imbricadas en un campo complejo de relaciones conformado por saberes, tradiciones, instituciones y efectos pragmáticos, que hacen de tales prácticas una auténtica sedimentación de lo que podemos reconocer como procesos culturales.

Los presupuestos que articulan esta propuesta se derivan de la experiencia de enfrentar, desde hace más de una década, la tarea de comprender las lógicas de producción de las artes plásticas y visuales, en una época en la que los pluralismos expresivos y los intercambios disciplinares tienden a relativizar los procesos que conciernen a la pregunta por el lugar de la investigación en la creación artística, al tiempo que las instituciones de arte y la academia usan y abusan del sentido de la relación investigar-crear en convocatorias, programas de formación y escenarios de legitimación del trabajo creativo, esquivando, no obstante, el debate sobre las reglas de juego para visibilizar los proyectos y la producción artística que promueven. Nuestra postura apunta a desplegar, a través de ciertas prácticas y procesos de configuración, algunas rutas para sustentar cómo no es posible producir arte con sentido, por fuera de una conciencia crítica de organiza- 
«La investigación-creación en el contexto de las prácticas estético-artísticas...»

ción y sistematización de los acumulados de la cultura, que problematicen la tradición, nuestras relaciones espacio-temporales, el vínculo de las obras con sus contextos particulares de producción, la experiencia del espectador y las narrativas más afianzadas por el arte y la estética.

Asumir que todo artista es un investigador o que quien crea al mismo tiempo investiga, se ha convertido en un comodín al que se recurre cada vez con mayor frecuencia, sobretodo en el campo de producción del arte actual cuando se reclaman orientaciones más claras para abordar la compleja relación entre investigación y creación. Situación que implica, tanto a los artistas formados dentro del paradigma tradicional, como a quienes apenas se adentran en las particularidades de sus programas de formación profesional. Claro que de este reduccionismo tampoco se escapan las instituciones y todo el sistema de organización y circulación del arte que tiende a homologar procesos y a homogeneizar el campo de producción de las ciencias humanas dentro de una misma lógica de producción de conocimiento.

Hasta hace muy poco parecía haber un consenso sobre lo que hacían los artistas: creaban obras de arte y punto. La preocupación por el trasfondo investigativo de la producción artística es reciente, -lo que no se traduce en que antes los artistas no investigaran- y obedece al agotamiento de los paradigmas configuradores que validaron la producción artística, casi hasta finalizar la segunda mitad del siglo XX. Un sondeo en los círculos más cercanos de artistas y formadores en las escuelas de arte hoy, sobre el tipo de creaciones que producen, nos puede ayudar a constatar cómo ha cambiado la percepción sobre la naturaleza de las cosas que hacen los artistas. A lo sumo, muchos dirán que hacen obras o que desarrollan series de un determinado tema, pero la gran mayoría hablarán de «proyectos» estéticos o artísticos, poniendo acento en alguno de los dos dominios o en ambos. En todos los casos, aludirán a complejos procesos de naturaleza disímil, gestados, no ya en talleres tradicionales, sino en sofisticados «laboratorios de investigación-creación», en los que las prácticas y los formatos más generalizados del arte son desplazados por enormes contenedores de información, archivos documentales y visuales, programas informáticos de autoedición para el manejo de texto y gráficos, o para la simulación o manipulación de imágenes en movimiento, entre otros. Por eso, muchos de los profesionales actuales del campo se cuidan de afirmar de plano que son artistas o que lo que realizan son obras de arte. Si se impone la noción del proyecto, como dispositivo abarcante para la organización de grandes corpus visuales y conceptuales que derivan en obra plástica o visual, o en ini- 
«La investigación-creación en el contexto de las prácticas estético-artísticas...»

ciativas de gestión, de curaduría, de movilización cultural e incluso de intervención social; si la noción de "proyecto», de raigambre "científica", en tanto responde al concepto clásico de la ciencia modernamente pensada, pasa aquí al dominio de la práctica artística con una amplitud tan grande como ambigua; si ya no se requieren talleres, sino laboratorios conformados por sistemas informáticos especializados, espacios específicos e inespecíficos, redes mediales o dispositivos de inmersión en espacios simulados, entre muchas otras posibilidades, entonces cabe preguntar ¿cuál es la lógica de producción que se impone en el campo de las prácticas artísticas contemporáneas y, de qué manera se patentiza la investigación en este modo de proceder?

\section{DE LA UNIDAD FORMAL A LA RETÓRICA VISUAL}

El arte es deudor de una larga historia en la que, por lo menos, se pueden reconocer tres grandes paradigmas de producción:

\subsection{La obra única}

El primero es el de la obra única, en el que no se diferencia espaciotemporalmente el momento de la concepción y el de la materialización de la obra. En este paradigma se ubican gran parte de los ismos de las vanguardias, con su impulso codificador y normatizador de la experiencia del arte y, especialmente, de la vida como forma de arte. Su singularidad parecía radicar, según Anna María Guash, en el "efecto shock" (Guash, 2011: 9) que debía producir la obra en un espectador afectable, al que, por demás, se le exigía un trasfondo cognitivo como garantía para alcanzar la experiencia estética que la obra prometía.

A pesar del convencionalismo formal que las sustentó, un estudioso de la pintura moderna como Filiberto Mena (1977: 13), encontrará en las prácticas de algunos vanguardistas como Cezanne, Seurat, Signac o Pissarro una actitud analítica, que apuesta por visibilizar un nuevo régimen de producción en el que proceso, comportamiento estético y concepto, empiezan a desviar la experiencia y la acción plástica hacia otros contextos organizativos. Tal actitud se concreta en un desplazamiento del plano de la expresión y la representación al plano de la reflexión, proponiendo una idea de arte que debe ser decantada en función de un saber-hacer, antes que en el mero objeto artístico. Es decir, que el artista se compromete con la construcción

Mediaciones Sociales, № 12, 2013, pp. 65-79. ISSN electrónico: 1989-0494.

DOI: http://dx.doi.org/10.5209/rev_MESO.2013.n12.45263 
«La investigación-creación en el contexto de las prácticas estético-artísticas...»

previa de la obra como concepto y acontecimiento antes que en su realización como acto. Un procedimiento que, como puntualiza Mena, empuja al artista a "empeñarse en la construcción de un discurso sobre el arte, en el mismo momento en que, de manera concreta, hace arte” (Mena, 1977: 10).

Como resultado de este giro emerge, lo que podríamos denominar, un filón para la investigación-creación artística, que despeja, primero, "la configuración de un campo de investigación sobre el sistema del arte”, y segundo, "una investigación sobre el sistema (o el subsistema) de la pintura" (Mena, 1977: 10). Los ejemplos que mejor ubican estos dos modos de proceder los encontramos, para el primer caso, en el arte conceptual, particularmente por la manera como estas prácticas interrogan la noción de arte, valiéndose para ello de un ejercicio progresivo de abstracción en el que las relaciones entre lenguaje e imagen, y entre representación y realidad, pierden la intención de ser un mero juego metafórico, justamente, porque como señala Jairo Montoya "tanto el arte como el lenguaje han abandonado ese lugar exterior de una mediación instrumental entre hombre y mundo en el cual pudieron ambos pensar desde la filosofía griega” (Montoya: 2008:193).

A partir de esta suerte de re-territorialización de la experiencia del arte y de la vida, se abre un lugar para aquellas prácticas artísticas que conjugan cuerpos abstraídos en expresiones proposicionales con otros cuerpos-lugares que hacen presencia o se visibilizan en sus propias inscripciones. En el orden configurador de la obra empieza a perder peso, entonces, la noción de la obra como facto, como cosa acabada, para ganar relevancia, en su lugar, la creación artística en términos de su organización procedimental. En todos los casos, el lenguaje cumple un rol que será dominante en el proceder del arte contemporáneo: sirve como "artificio retórico, -se configura como- una especie de mnemotécnica, para elevarse de lo sensible a lo abstracto, de la fisicidad de la cosa (objeto, imagen, palabra), a los procedimientos mentales que actúan en la formación del arte y de sus estatutos valorativos" (Montoya, 2008: 11). En el contexto de las prácticas artísticas en Colombia artistas como Antonio Caro, Bernardo Salcedo, Álvaro Barrios y, más recientemente, Johanna Calle han sido claves para visibilizar estos procesos en toda su complejidad sintáctica, semántica y expresiva.

El segundo caso, nos lo amplía el gran repertorio de transformaciones que empieza a sufrir la pintura en el momento en que, tanto la idea y como la ejecución, son sometidos a un proceso de formalización, que busca afian- 
«La investigación-creación en el contexto de las prácticas estético-artísticas...»

zar la autonomía expresiva del medio plástico, al tiempo que se apela por la configuración de un sistema formal para la pintura. La concepción interna del plano representacional en unidades y formas progresivas, que luego alcanzarían su coherencia y articulación en un soporte determinado, permitieron a los artistas que optaron por esta vía, como Seurat y Cezanne, para nombrar sólo algunos, tomar distancia con los mecanismos perceptivos que impulsaron los impresionistas, para privilegiar, en su lugar, la concepción de lo procedimental y la resignificación de los signos del lenguaje visual, en relación con el contexto particular que demandaba cada creación. En cierto modo este proceder configura un ejercicio de desvelamiento en el que, de acuerdo con Mena, el cuadro como ícono de completitud parece perder peso, se desmaterializa en su densidad, dejando entrever la trama estructural de la pintura como tal: su lógica interna (Mena, 1977: 15).

Dado que nuestro interés radica en mostrar también estos procesos en obras que nos son más familiares en los circuitos del arte en Colombia, podemos señalar, en este caso, el trabajo de Luis Caballero, especialmente su obra "La cámara del amor" de 1968, en la que el artista despliega la acción del pintar y el acto de ver, por fuera del plano cerrado del «cuadro cuadrado». Además de fragmentar el motivo y escenificar su puesta en obra, a la manera de la instalación, este trabajo de Caballero también anticipa una nueva experiencia visual para el espectador, toda vez que replantea su relación con la obra y con el espacio expositivo. Del mismo modo podemos hablar de la obra de Beatriz González, especialmente las series "Los suicidas del Sisga I y II" de 1965, la serie preparatoria "Boceto para 1/500", "Estudio para 1/500" y el montaje serigráfico "1/500", de 1992, así como su serie "Las Delicias" de 1997; series en los que González trabaja reiteradamente sobre un mismo motivo, variando su cromatismo y su gestualidad, pero insistiendo, en todos los casos, en desnaturalizar imágenes banalizadas por los medios de comunicación impresos, para recuperarnos en el asombro, en el significado, en todo el gesto arrebatado por la retórica mediática.

Aunque a nivel de soportes y medios este primer paradigma no traspasa los dominios técnicos más tradicionales -óleos sobre lienzo o sobre madera-, es posible leer aquí una clara apuesta por la instauración de una nueva proxémica del acto de ver, por la inscripción de nuevas textualidades visuales y la reescenificación del espacio de recepción de las obras, con el consecuente reforzamiento de las funciones, modos de transmisión y circulación en las prácticas estético-artísticas actuales. 
«La investigación-creación en el contexto de las prácticas estético-artísticas...»

\subsection{Lo discontinuo, lo plural, lo dislocado}

Un segundo paradigma lo ubicamos en los procesos de multiplicación y fragmentación del objeto artístico, su desestructuración y dispersión expresiva bajo la forma del collage y del collage montaje. Esta perspectiva desestructurante, que nace con el cubismo, constituye una derivación del paradigma anterior en la medida en que realiza la tendencia que ya se intuía en la pintura analítica, de detonar las bases de la representación formal. La finalidad del procedimiento que plantea la emergencia del collage tiene valor para la comprensión de las relaciones entre investigacióncreación, en la medida en que abre, por un lado, la tendencia al apropiacionismo y, por el otro, materializa la estrategia mnemotécnica de inventar o figurar un espacio otro, enteramente fragmentario, que rompe con la noción de un espacio-soporte continuo, e introduce la posibilidad de una nueva figuración, basada en la diferencia y la inserción de lo cotidiano en el espacio de la obra.

La apropiación, y fundamentalmente la apropiación crítica, configura una estrategia revolucionaria, de carácter intertextual, de interrelación y relectura de corpus de naturaleza y materialidad disímil, que por vía de recursos como la citación, el plagio o la alusión, se hacen un lugar en la práctica del arte. Como estrategia creativa y discursiva, la apropiación y la transferencia señalan un actitud reflexiva y crítica, si se quiere, en relación con lo que se relee y reescribe, se presta o se transfiere, se importa o se hace migrar, dado que implica una toma de conciencia sobre el modo como opera un determinado campo de producción, los contenidos que moviliza y los circuitos que lo dinamizan.

En la concreción que singulariza la puesta en obra, el apropiacionista se desplaza de manera libre entre el representar y el presentar, entre la edición y el ready-made, entre el denominar y el señalar, dislocando las formas, jugando con el sentido y la referencialidad, a medida que sustituye "los medios expresivos -ya gastados- de la tradición por los materiales creados por las nuevas condiciones de vida" (Mena, 1977: 37). Un replanteamiento revolucionario que, al lado del paradigma vanguardista muestra el tránsito de una problemática creativa desestructurante que pone en crisis el sistema orgánico del arte, para extender, en sentido amplio, las posibilidades de la creación artística. En esta distensión de dominios se afianza la relación del artista con elementos y objetos del mundo cotidiano 
«La investigación-creación en el contexto de las prácticas estético-artísticas...»

lo que, a su vez, se convierte en estímulo para implantar nuevas políticas de la visualidad en las que la autorreflexividad y el diálogo con lo plural devienen verdaderas estrategias transfiguradoras del sentido.

En la consideración que nos ocupa, la particularidad de este tipo de prácticas radica en el hecho de que la mayoría emergen en condiciones en las que "el formato reglamentario" (Richard, 2007: 29), de configuración única resulta insuficiente como dispositivo para exteriorizar la intensidad del obrar estético y material de las obras. La custodia de ciertos valores formales y de estructuras conformativas, afianzadas en la sublimación de la experiencia del yo del creador, ha hecho de la estrategia normativa, y por ende institucional, un recurso político, usado para afianzar "un repertorio fijo de valores inalterables" (Richard, 2007: 29) que, desde la perspectiva dictatorial de quien los regenta, deben ser protegidos contra la amenaza del desorden, del caos, de la contaminación que representa el arte actual. Al subvertir los encuadres normativos, tanto desde lo procedimental, como desde lo conceptual, la creación en clave de investigación posibilita otras experiencias de pensamiento y transmisión en las que se amplían los repertorios configuradores, anticipando, de manera particular, nuevos comportamientos en todo el sistema de organización y circulación del arte.

Desde este contexto podemos hablar de un artista como Bernardo Salcedo con su serie "Cajas" (1966), en las que ensamblaba fragmentos de objetos de diferente procedencia, jugando con la antiforma, lo arbitrario y lo irónico. Igualmente podemos hablar de una artista como Ethel Gilmour, quien a partir de elementos míticos y objetos cotidianos, muchos de ellos circunscritos a la vida doméstica y a los estereotipos de la realidad colombiana reconfigura una posibilidad de acercamiento a la historia de la violencia y muerte que ha vivido el país desde mediados del siglo XX.

\subsection{El arte como archivo}

El tercer paradigma cobija aquellas experiencias artísticas que toman como punto de partida la lógica del archivo como sistema de memoria material. Los inventarios de imágenes, objetos, registros visuales, fotografías, documentos históricos, entre otros, constituyen un recurso fundamental en los procesos de configuración y puesta en obra de artistas y curadores contemporáneos, y muestran el deslinde de las prácticas artísticas hacia otras disciplinas como la historia, la etnografía, la sociología, entre otras, a las cuales tiende a desafiar en sus límites y metodologías, proyec-

Mediaciones Sociales, № 12, 2013, pp. 65-79. ISSN electrónico: 1989-0494.

DOI: http://dx.doi.org/10.5209/rev_MESO.2013.n12.45263 
«La investigación-creación en el contexto de las prácticas estético-artísticas...»

tando derivas poco convencionales para construir, por ejemplo, las relaciones entre teoría y práctica.

De acuerdo con Anna María Guash, hasta los años 90 no se patentiza la tendencia que toma en consideración la práctica artística "como archivo". Esta tendencia, que implica una nueva manera de considerar lo otro en la conformación de la propia experiencia creativa, se expresa, fundamentalmente, "en la voluntad de transformar el material histórico oculto, fragmentario o marginal en un hecho físico y espacial, caracterizado por su interactividad” (Guash, 2011: 163). De la esfera privada a la pública, del constructo documental al visual, del soporte físico al digital, las creaciones artísticas en clave de archivo comportan una operatividad dinámica, son registros del registro, mnemotecnias reactivas que abren otras posibilidades para reescribir la memoria, sobretodo cuando la cultura digital se vuelve dominante con sus formas de almacenamiento, clasificación y circulación de estas producciones.

En la experiencia particular de investigación que me ha ocupado en los últimos años, las prácticas artísticas que toman como punto de partida el paradigma del archivo son tributarias de unos procesos creativos integrados, que atienden a la discontinuidad de los relatos menores por vía del recurso de la deconstrucción formal y semiótica. Para Anna María Guash, la función del arte, en este sentido, "no es afirmar la tradición sino encontrar «algo nuevo» en cada instante, un instante entendido como «tiempoahora» (al margen de los nexos causales que establece el historicismo) que condensa en sí mismo la historia del pasado" (Guash, 2010: 165).

Sin duda alguna, los diferentes contextos de violencia política en Colombia y América Latina han sido uno de los principales estímulos para el trabajo etnográfico y el ejercicio archivístico de carácter crítico de un artista como José Alejandro Restrepo, quien desde experiencias que bien podríamos denominar de iconofilia e iconoclastia, se ha ocupado de desestructurar las grandes narrativas nacionales, contrarrestando su peso con gestos y acciones plásticas en las que se revelan nuevos desafíos éticos, estéticos y políticos. Esto es precisamente lo que logra en trabajos como "El paso del Quindío 2", desarrollado entre 1996 y 1998. En esta obra el artista se vale de una serie de imágenes en video en las que aparece un silletero o carguero, de los que todavía transitan por algunos caminos del Chocó colombiano. Estas imágenes en movimiento son puestas en relación con grabados e ilustraciones provenientes de la Geografía pintoresca de la 
«La investigación-creación en el contexto de las prácticas estético-artísticas...»

Nueva Granada y con textos relatados por cronistas del Siglo XIX, en un intento por visibilizar el micro poder que concentra la práctica del carguero. ¿Quién domina a quién? Esa parece ser la pregunta que pone a circular el artista José Alejandro Restrepo en esta instalación, tomando como referencia un planteamiento de Foucault en el que señala cómo el poder se define por singularidades (Foucault, 1979). De cara a los relatos de la historia y a su retórica visual el modo como en esta obra se usan los archivos históricos nos posibilita deconstruir las relaciones espacio-temporales frente a nociones como discontinuidad, progreso y desarrollo, al tiempo que se refuerzan la idea de que los archivos practicados son referentes que hablan, transmiten ideas, problematizan miradas y, en todos los caso, se vuelven procesualidad.

En el mismo sentido podemos hablar de la serie "Las Delicias" (1997) de Beatriz González. Como es propio de su trabajo, en ella la artista recurre a imágenes mediales, escenografías y expresiones que se repiten cotidianamente a través de los medios masivos, particularmente por los medios impresos, para re-crear el modo como se alude a la violencia política en Colombia. La serie surge a partir del ataque perpetrado por el grupo guerrillero de las FARC a la base militar de Las Delicias, en el Putumayo, el 30 de agosto de 1996, donde murieron 31 militares, 17 quedaron heridos y 60 fueron secuestrados. Inicialmente, la artista proyecta realizar una serie de 365 obras, ejecutando una por día, no obstante, la serie se concreta en 30 pinturas sobre lienzo entre las que sobresale "Mátenme a mi que yo ya vivî", pintura que toma como referencia un artículo publicado en el periódico El Tiempo, titulado "Mátenme a mi que yo ya viví lo suficiente" y que alegoriza el drama y la impotencia de las madres, frente a la determinación de los violentos. El interés por recuperar de los medios masivos repertorios de imágenes, de gestos, y comportamientos cotidianos le posibilita a González re-codificar la realidad y sus circunstancias, reescribiéndola en materialidades y gestos que precisan siempre un vínculo transmisible para su comparecencia como forma cultural.

\section{Conclusiones}

\section{El arte no progresa, se acumula}

A pesar del movimiento que sustentan los tres paradigmas referidos, hasta ahora nadie se ha atrevido a decir que las producciones artísticas 
«La investigación-creación en el contexto de las prácticas estético-artísticas...»

estén impulsadas por el ritmo que marca el progreso, o por el vector que impulsa la evolución. Desplazamiento, ruptura, retorno, mutación, deconstrucción, resistencia, simulacro, apropiación o reapropiación, son algunas de las estrategias de las que se ha valido la creación artística para dar cuenta de su relación paradojal entre permanencia y cambio, en cuya apuesta se afianza el lugar que el arte ocupa en la cultura. A esta relación hace referencia Francois Dagognet cuando señala que los procesos del arte nos han colocado frente a una suerte de "revolución acumulativa" (Dagognet, 1999: 32) que, no obstante la aparente estaticidad y la densificada conformación de sus productos, se nos presentan como potentes dispositivos culturales, claves para actualizar la discusión sobre los valores formales y expresivos de las obras, sus lógicas de configuración, sus modos de circulación social y transmisión en el tiempo.

Lograr una conciencia plena de esta condición no es tarea fácil, pues el impulso que nos domina tiende a estar más conectado con aquella racionalidad que busca establecer linealidades y conexiones causales, aún en relación con los fenómenos culturales. Por eso el desafío que enfrentan las prácticas estético-artísticas hoy radica en reconocer, generosamente, en esta inestabilidad el potencial para un ejercicio, que al tiempo que reclama una actitud crítica de apertura permanente, también exige configurar procesos de mayor alcance, en los que la idea de esa "revolución acumulativa" de la que habla Dagognet, se piense con relación al propio contexto del artista, de tal manera que al lado de la noción de PROYECTO se convierta en una alternativa para canalizar, organizar y articular la profusión de recursos expresivos, motivos, registros soportes, saberes y sistemas configuradores que pueden llegar a tener cabida en las prácticas del arte actual.

Es la multiplicidad y no la singularidad la que determina el rasgo epocal de la creación artística contemporánea. Así lo sustentó José Luis Brea en su texto "El fin de la obra singular", al establecer que

"el tiempo en que las artes tenían por misión respaldar el imaginario de un mundo de los seres particulares es un tiempo pasado, muerto. Y felizmente muerto, por negador del ser en su despliegue infinitésimo e innumerable, como epifanía radical de la diferencia" (José Luis Brea, 2004: 34).

La sucesión entre sistemas de producción y reproducción configura un motor para la cultura, y una estrategia renovadora para deponer lo absoluto, 
«La investigación-creación en el contexto de las prácticas estético-artísticas...»

lo estable y lo excluyente como preceptos de la creación artística a favor de lo pluriforme, lo inestable, lo incluyente.

La perspectiva que se abre en la consideración de las relaciones entre investigación y creación artística es aquella que ve en el movimiento expansivo y transfigurador del obrar del arte la posibilidad de reconfigurar permanentemente el "nuevo objeto" que emerge de sus reacomodamientos temporales, en atención a los procedimientos y a las apuestas expresivas que median entre los ámbitos de producción y de recepción de las obras. De manera consecuente con su naturaleza indeterminada y abierta, la comprensión de tal densidad reclama un abordaje capaz de mostrar la lógica de este campo de producción de sentido, en relación con los entredichos, las valoraciones, los límites y las transgresiones que el plexo de las prácticas estético-artísticas de nuestro tiempo plantean.

En su práctica, el arte se ha valido de usurpaciones y trasteos, de préstamos e intercambios para llegar a consolidar el amplio y complejo campo de maniobra en el que se mueve actualmente. No obstante, faltan luces para organizar este horizonte de intervenciones y búsquedas; nos hace falta hallar categorías que desalojadas de los viejos atavíos epistemológicos y pragmáticos creados por otras disciplina, nos permitan organizar las prácticas y los comportamientos que nos conciernen, dentro de una lógica otra, menos resistente a comprender y potencializar los modos como se desenvuelve y opera este campo en la actualidad. Esta búsqueda y posible intervención, debe involucrar, además de los programas formativos ofertados por las universidades, los ámbitos de la escuela y de la educación no formal, en los que suelen replicarse, sin mucho discernimiento, los discursos y las posturas que se ponen a circular desde los centros dominantes de la institucionalidad, porque desde allí se pueden tejer condiciones de intercambio y retroalimentación que, de manera también procesual, vayan generando impactos en el mediano y largo plazo, en los modos de percibir, comprender y transmitir las producciones artísticas.

\section{Bibliografía}

BREA, J. L. (2004): El tercer umbral. Estatuto de las prácticas artísticas en la era del capitalismo cultural. España: CENDEAC. 
Dagognet, F. (1999): Por el arte de hoy. Del objeto del arte al arte del objeto. (París: Dis Voir, 1992). Trad. de María Cecilia Gómez B., Documento sin publicar - Universidad Nacional de Colombia - sede Medellín, Comité de Investigaciones y Desarrollo de las Ciencias - CINDEC.

Foucault, M. (1979): Microfísica del poder. Trad. De Julia Varela y Fernando Álvarez-Uría. Madrid: Edissa.

GuAsh, A. M. (2011): Arte y archivo, 1920-2010. Genealogías, tipologías y discontinuidades. Madrid: Akal.

MenA, F. (1977): La opción analítica en el arte moderno. Barcelona: Ed. Gustavo Gili.

Montoya, J. (2008): Explosiones lingüísticas, expansiones estética. Medellín: Universidad Nacional de Colombia.

RicHARD, N. (2007): Fracturas de la memoria. Arte y pensamiento crítico. Argentina: Siglo XXI Editores. 


\section{PARA CITAR ESTE TRABAJO EN BIBLIOGRAFÍAS:}

CALLE, Margarita (2013): "La investigación-creación en el contexto de las prácticas estético-artísticas contemporáneas. Desplazamientos disciplinares y desafíos institucionales", Mediaciones Sociales. Revista de Ciencias Sociales y de la Comunicación, $\mathrm{n}^{\circ} 12$, pp. 65-79. DOI: http://dx.doi.org/10.5209/rev_MESO.2013.n12.45263

\section{${ }^{(*)}$ La autora}

Profesora titular del Departamento de Humanidades e Idiomas de la Facultad de Bellas Artes y Humanidades de la Universidad Tecnológica de Pereira, donde dirige la Maestría en Estética y Creación, y coordina el Grupo de Investigación en Arte y Cultura, y la línea de investigación en arte contemporáneo. Autora de los libros Metáforas urbanas, el artista y la ciudad, premio de ensayo, Instituto de Cultura de Pereira, 2003; Perspectivas históricas del desarrollo de las artes plásticas en Pereira, Universidad Tecnológica de Pereira, 2006; y, Mutaciones y registros. Desplazamientos y convergencias del arte contemporáneo en Colombia, Universidad Tecnológica de Pereira, 2011. El presente texto hace parte de las reflexiones derivadas del proyecto "Decentramientos estéticos y prácticas artísticas contemporáneas. La paradoja de las identidades y la negociación cultural". Ellas a su vez articulan nuevos desarrollos en el proyecto "El arte como archivo, lo otro como testimonio, el artista como testigo", desarrollado desde el Grupo de Investigación en Arte y Cultura, línea de investigación en Arte Contemporáneo, en coautoría con el profesor Felipe Martínez Quintero.

RECIBIDO: 21 de enero de 2013.

ACEPTADO: 04 de septiembre de 2013. 